\title{
Learning the Science Behind Bacteriocins Through Lacticin 3147; a Promising Lantibiotic
}

\author{
Allison Wan ${ }^{1}$, Cherry Ibarra-Romero ${ }^{1}$, John Vederas ${ }^{1}$ \\ ${ }^{1}$ Department of Chemistry, University of Alberta
}

\begin{abstract}
As microorganisms continue to develop resistance and survive against many different forms of antimicrobial solutions, such as antibiotics, the threat that antimicrobial resistance poses grows considerably. One solution to this persistent issue could be bacteriocins: ribosomally synthesized antimicrobial peptides that are synthesized by bacteria. In this study, the specific lantibiotic-a subclass of bacteriocin-used was lacticin 3147, which is comprised of two components: A1 and A2. Lacticin 3147 was first purified and isolated in order to properly analyze its antimicrobial effects, which show potential use in antibiotics or food preservation. The procedure started with growing the producer bacteria strain, Lactococcus lactis DPC 3147 in a broth which was later used to inoculate a large volume of media. This media was then separated through centrifugation into two components: the supernatant and cell pellet, both of which were each individually concentrated and purified through a series of columns. Approximately one milliliter of each component was run through a High Performance Liquid Chromatography (HPLC) machine, and the resulting chromatograms interpreted to evaluate and compare the concentrations of lacticin 3147 produced in the liquid media portion (supernatant) and the cell components (cell pellet). Subsequently, fractions were collected from all runs from the HPLC and further subjected to Matrix Assisted Laser Desorption Ionization Time of Flight (MALDI TOF) mass spectrometry. This allows to test the molecular weights of the compounds in the samples to check if they aligned with the known molecular weights of both the A1 and A2 components of lacticin 3147. The final step was to prepare a spot on lawn assay using the indicator species: Lactococcus lactis subsp. cremoris HP. The spot on lawn assay prepared for lacticin 3147 was a visual indicator of the strong antimicrobial effects of the bacteriocin. Ultimately, this highly effective bacteriocin, lacticin 3147 , could be utilized in smaller concentrations than current antibiotics, and thus shows great promise in the field of antibiotics. Further studies are being conducted to understand the interactions between the A1 and A2 components of lacticin 3147, including their synergistic effects.
\end{abstract}

Key words:

Bacteriocin, Lacticin, bacteria, Lactococcus lactis, Lactococcus lactis bacteria, antimicrobial resistance, purification, purification of bacteria

Cite as: Wan A., Ibarra-Romero C., Vederas J. 2019. Learning the Science Behind Bacteriocins Through Lacticin 3147; a Promising Lantibiotic. Alberta Academic Review, Vol 2 (2) 79-80, WISEST Special Issue (non peer-reviewed), DOI 10.29173/aar75. 
Wan et al., 2019

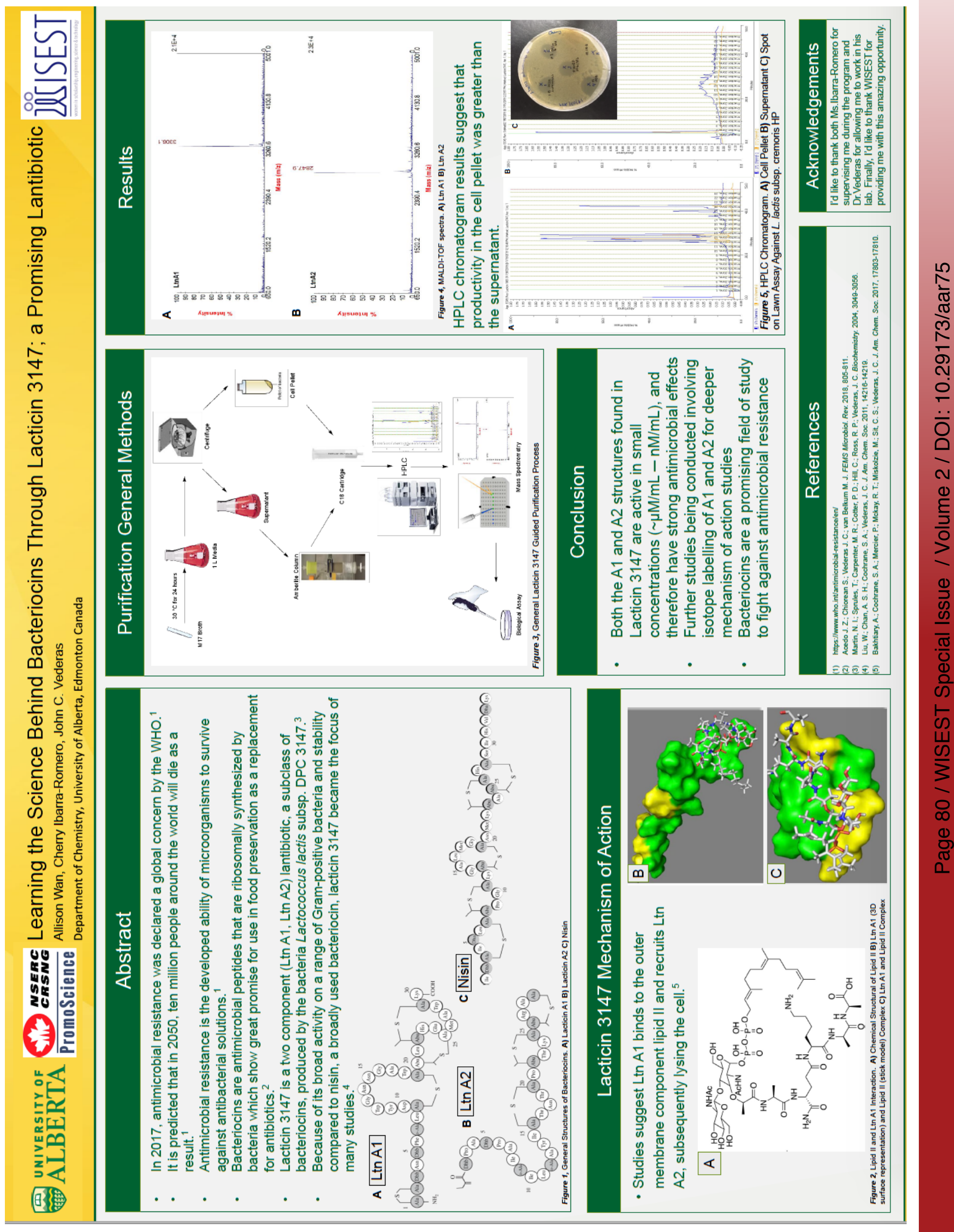

